\title{
MASCC RECOMMENDATIONS ON THE MANAGEMENT OF CONSTIPATION IN PATIENTS WITH ADVANCED CANCER
}

\section{AUTHORS}

Dr Andrew Davies, Speciality Lead for Supportive \& Palliative Care Royal Surrey County Hospital, Guildford, United Kingdom

ORCHID ID: 0000-0003-4207-4799

Dr Charlotte Leach, Clinical Research Fellow in Palliative Medicine Royal Surrey County Hospital, Guildford, United Kingdom ORCHID ID: 0000-0002-4724-2600

Dr Ricardo Caponero, Coordinator of Advanced Centre for Supportive Therapy and Integrative Medicine

Hospital Alemão Oswaldo Cruz, São Paulo, Brazil

ORCHID ID: 0000-0001-8443-9229

Dr Andrew Dickman, Consultant Pharmacist

Royal Liverpool Hospital, Liverpool, United Kingdom

ORCHID ID: 0000-0001-6493-8979

Dr David Fuchs, Hematologist and Medical Oncologist

Kepler University Hospital, Linz, Austria

ORCHID ID: 0000-0002-9968-1576

Dr Judith Paice, Research Professor of Medicine (Haematology and Oncology)

Northwestern University, Chicago, United States of America

ORCHID ID: 0000-0001-7534-1756

Dr Anton Emmanuel, Consultant Gastroenterologist

University College London Hospitals, London, United Kingdom

ORCHID ID: 0000-0001-6730-818X 


\title{
CORRESPONDING AUTHOR
}

Dr Andrew Davies, Speciality Lead for Supportive \& Palliative Care

Royal Surrey County Hospital, Egerton Road, Guildford, GU2 7XX, United Kingdom

Email: adavies12@nhs.net

Telephone: 01483571122 ext 2043

\begin{abstract}
Purpose: The Palliative Care Study Group of the Multinational Association for Supportive Care in Cancer formed a sub-group to develop evidence-based recommendations on the management of constipation in patients with advanced cancer
\end{abstract}

Methods: These recommendations were developed in accordance with the MASCC

Guidelines Policy. A search strategy for Medline was developed, and the Cochrane Database of Systematic Reviews and the Cochrane Central Register of Controlled Trials were explored for relevant reviews / trials respectively. The recommendations were categorised by the level of evidence, and a "category of guideline" based on the level of evidence (i.e.

"recommendation", "suggestion", or "no guideline possible")

Results: The Group produced 15 recommendations, with varying levels of evidence, and so varying categories of guideline. The recommendations relate to the assessment, the treatment, and the re-assessment of constipation.

Conclusions: These recommendations provide a framework for the management of constipation in advanced cancer, although every patient needs individualised management.

\section{KEYWORDS}

Constipation; neoplasms; palliative care; practice guideline 


\section{INTRODUCTION}

Constipation is a common problem in patients with advanced cancer, and is the cause of significant morbidity in this group of patients. However, observational studies suggest that constipation is not well managed in patients with advanced cancer [1]. The reasons for the latter are multiple, and include inadequate assessment, inappropriate treatment, and inadequate re-assessment (and assess response to treatment). Moreover, non-adherence to clinical guidelines [2], and non-adoption of new interventions [3], appear to be common occurrences.

On the basis of the above, the Palliative Care Study Group of the Multinational Association for Supportive Care in Cancer (MASCC) formed a sub-group to develop evidence-based recommendations on the management of constipation in patients with advanced cancer. [The group received no internal / external funding to support the process]. This paper gives an overview of constipation in patients with advanced cancer, the methodology involved in developing the recommendations, and the evidence to support the recommendations (and the grading of the evidence).

At the time the Group started the project there were no up-to-date guidelines on the management of constipation in patients with advanced disease. However, in the interim, the European Society of Medical Oncology (ESMO) have published analogous guidelines [4]. Our recommendations complement the ESMO guidelines, but they provide more detailed guidance on the pharmacological management of refractory constipation (of differing aetiology).

\section{BACKGROUND}

\section{Definition}

The Oxford Concise Medical Dictionary defines constipation as "a condition in which bowel evacuations occur infrequently, or in which the faeces are hard and small, or where passage of faeces causes difficulty or pain" [5]. Indeed, the term "constipation" means different things to different people [6], which has implications for the management of constipation. For example, a Swedish survey of the general population reported that $23.8 \%$ female respondents, and $24.3 \%$ male respondents, considered "straining in connection with bowel movement" was not indicative of constipation [7]. Similarly, a Korean survey of constipated individuals 
reported that $48.3 \%$ respondents considered "using fingers to help empty your bowel" was not indicative of constipation [8].

\section{Aetiology}

The Rome Foundation categorise constipation as being either functional constipation, or secondary constipation [9]. Functional constipation is a heterogeneous phenomenon, and can be subdivided into normal-transit constipation, slow-transit constipation, and defaecatory or rectal evacuation disorders [9]. The risk factors for functional constipation include a positive family history, low levels of dietary fibre, and low levels of physical activity [9]. Secondary constipation may have a variety of different causes, including gastrointestinal diseases (e.g. diverticulosis, irritable bowel syndrome), neurological / psychiatric diseases (e.g. dementia, depression), other systemic diseases (e.g. diabetes, hypothyroidism), and / or medications (e.g. antacids, diuretics) [6].

Opioid-induced constipation is a subtype of secondary constipation, with a distinct pathophysiology (Box 1), which is primarily a peripheral effect, and primarily a mu-opioid receptor effect [10]. Opioid-induced constipation appears to be more common in patients with cancer pain (than non-malignant pain) [9], may be influenced by genetic factors [11], and may be influenced by the type of opioid utilised [12]. However, opioid-induced constipation does not appear to be particularly influenced by the dose of opioid utilised [13]. Opioid-induced constipation tends to be a chronic side effect, although some patients appear to develop tolerance over time [13]. Unsurprisingly, the pathophysiology has important implications in relation to the management [14].

\section{INSERT BOX 1 ABOUT HERE}

\section{Epidemiology}

Constipation is a common problem, with most people experiencing the symptom at some point in their life. The reported mean prevalence of functional constipation in the general population is $14 \%$ (range $1.9-40.1 \%$ ), with a mean prevalence of $15 \%$ using self-assessment, and a mean prevalence of $6.8 \%$ using the Rome Foundation diagnostic criteria (i.e. Rome III diagnostic criteria) [15]. 
The reported prevalence of constipation in patients with advanced cancer is $32-87 \%$, which reflects variable methods of assessment as well as different study populations (e.g. inpatients generally have a higher prevalence than outpatients) [16]. Similarly, the reported prevalence of opioid-induced constipation in patients with cancer pain is 5-97\%, which again reflects variable methods of assessment as well as different study populations [17].

\section{Clinical features}

The clinical features vary from patient to patient, and include symptoms relating to constipation, and / or symptoms resulting from the complications of constipation (i.e. local, systemic).

An American survey of constipated (functional constipation) individuals reported the frequency of different symptoms relating to constipation: straining (79\%), "gas" (74\%), hard stool (71\%), abdominal discomfort (62\%), infrequent defaecation (57\%), bloating (57\%), sensation of incomplete evacuation (54\%), abdominal pain (48\%), rectal pain (41\%), and sudden urge for defaecation (35\%) [18]. Moreover, 52\% of individuals reported that constipation significantly affected their quality of life (i.e. "somewhat", "a lot", or "a great deal") [18].

The local complications of constipation include faecal impaction, faecal leakage / "overflow diarrhoea", gastrointestinal obstruction, gastrointestinal perforation, rectal prolapse, haemorrhoids, anal tears, rectal bleeding, urinary tract infection, and urinary retention [16]. Patients may also experience upper gastrointestinal problems such as halitosis, anorexia, early satiety, nausea and vomiting, and gastro-oesophageal reflux ("heartburn"). The systemic complications of constipation include general malaise, confusion / delirium, and headache [16]. Uncommonly, constipation can indirectly cause the death of an individual (e.g. faecal impaction causing gastrointestinal perforation; straining causing pulmonary embolism) $[19,20]$.

Constipation is associated with various psychological problems, including anxiety, depression, and even "catastrophic thinking" (e.g. "I thought you would die, blow up inside") [21]. Moreover, it can lead to negative social outcomes such as avoidance of family / friends, and avoidance of public places (and so social isolation) [22]. 
Constipation is also associated with a significant health economic burden: constipation leads to increased "direct costs" (e.g. costs of intervention, costs of healthcare professional), and increased "indirect costs" (e.g. costs of travel, costs of decreased productivity), which impacts on the patient, the health service and the wider society [23].

Of concern patients with opioid-induced constipation may reduce the dose of opioid analgesic, or even stop the opioid analgesic, in order to overcome the associated distress and discomfort (which usually results in worse cancer pain) [24].

\section{METHODS}

The aim of the Group was to develop comprehensive, clinically-relevant, evidence-based recommendations on all aspects of the management of constipation in patients with advanced cancer. Thus, it was agreed that the recommendations could include ones supported by "high" levels of evidence (e.g. systematic reviews), as well as ones supported by "low" levels of evidence (e.g. expert opinion), if the topic was deemed to be clinically-relevant.

The recommendations were developed in accordance with the MASCC Guidelines Policy [25]. The Group adopted the National Cancer Institute (NCI) definition of advanced cancer (i.e. "cancer that has spread to other places in the body and usually cannot be cured or controlled with treatment") [26], and data was included from studies involving cancer patients still receiving anti-cancer treatment, and also cancer patients only receiving palliative care (or both modalities).

A search strategy for Medline was developed (Appendix 1), and the Cochrane Database of Systematic Reviews and the Cochrane Central Register of Controlled Trials (CENTRAL) were explored for relevant reviews / trials respectively [27,28]. The review of the published literature was restricted to papers written in English, and to papers relating to adult ( $>18$ years) humans.

All abstracts identified by the search of Medline (1946 - present) were downloaded into a reference management software package. These abstracts were independently assessed for relevance by the two main authors $(\mathrm{AD}, \mathrm{CL})$, and if one author deemed the abstract relevant, then the full text of the article was obtained. These articles were independently assessed for inclusion by the two main authors. All the authors were involved in assessing the randomised 
controlled trials in the CENTRAL, and the two main authors were involved in assessing the systematic reviews in the Cochrane Database of Systematic Reviews.

Whenever possible the recommendations were based on data from patients with advanced cancer. However, when no data was available, or only poor quality data was available, data from other populations was extrapolated (if deemed appropriate). For example, the evidence for the peripherally acting mu-opioid receptor antagonists is mainly from studies involving patients with non-malignant pain (rather than patients with cancer pain). However, it is generally accepted that the efficacy of such drugs is not related to the underlying condition [29], although the tolerability may be influenced by the underlying condition and/or comorbidities.

The recommendations were characterised by a level of evidence (i.e. I, II, III, IV, or V), and a "category of guideline" based on the level of evidence (i.e. "recommendation", "suggestion", or "no guideline possible") (Appendix 2) [25]. The recommendations were independently characterised by the two main authors (AD, CL), and a consensus reached in the case of any disagreement. [All of the authors agreed with the recommendations / characterisations of recommendations].

\section{RESULTS}

The searches were last undertaken on $19^{\text {th }}$ April 2019. The Medline search identified 2775 references, and 260 full text articles were retrieved (and reviewed). The search of the Cochrane Central Register of Controlled Trials (utilising the keywords "constipation" and “cancer") identified 1925 references, and 54 articles were formally reviewed. Similarly, the search of the Cochrane Database of Systematic Reviews (utilising the keyword “constipation") identified 23 references, and 10 reviews were formally reviewed.

The Group produced 15 recommendations (see below), with varying levels of evidence, and so varying categories of guideline.

\section{RECOMMENDATIONS}

The recommendations of the Group are summarised in Table 1 (with the levels of evidence, and the categories of guideline). Moreover, the Group recommend that all pharmacological 
interventions are used in accordance with their Summary of Product Characteristics, i.e. that prescribers follow the prescribing guidance (e.g. dose, dose frequency), and take note of relevant contraindications, cautions, interactions, and adverse effects.

\section{INSERT TABLE 1 ABOUT HERE}

\section{Recommendation 1 - All patients with advanced cancer should be regularly assessed for constipation [Level of evidence - V; category of guideline - suggestion].}

The objectives of assessment are to determine: a) the presence of constipation; b) the aetiology of constipation (i.e. functional, secondary); and c) other factors that may influence the choice of intervention. Inadequate assessment may result in initiation of inappropriate interventions (or even contra-indicated interventions).

The assessment of constipation involves primarily taking a detailed history, and performing an appropriate examination (i.e. clinical assessment). The history should include the questions outlined in Box 2 [6,9], and the use of the Bristol Stool Chart (to assess stool consistency) [30]. The examination should include an abdominal examination, and ideally a digital rectal examination $[6,31]$.

\section{INSERT BOX 2 ABOUT HERE}

The Rome Foundation diagnostic criteria are generally employed to diagnose functional gastrointestinal disorders. The Rome IV criteria for functional constipation are shown in Table 2 [9]. Of note, the validation studies of these criteria reported a relatively low sensitivity of $32.2 \%$, a relatively high specificity of $93.6 \%$, and "moderate" reliability [32]. The new Rome IV criteria for opioid-induced constipation are also shown in Table 2 [9]. Currently, there are no published validation studies of these criteria.

\section{INSERT TABLE 2 ABOUT HERE}

Observational studies suggest that plain abdominal X-rays may be helpful in assessing patients with constipation [33], including patients with advanced cancer [34]. However, more specialised gastrointestinal investigations should be limited to patients with "resistant" 
constipation in patients with advanced cancer (and should be undertaken by gastroenterologists with an interest in constipation) [9].

Recommendation 2 - The management of constipation should be individualised [Level of evidence - V; category of guideline - suggestion].

The management of constipation should be individualised, and depends on: a) aetiology of constipation (e.g. functional, opioid-induced); b) clinical features of constipation (e.g. faecal impaction, stool in rectum); and c) patient-related factors (e.g. personal preferences, comorbidities).

\section{Recommendation 3 - Patients should be offered adequate privacy, and appropriate} equipment (e.g. commode, foot stool), to promote defaecation [Level of evidence - V; category of guideline - suggestion].

Observational studies of patients with advanced cancer have shown an association between constipation and lack of privacy (for defaecation) [35]. Hence, whenever possible patients should be supported to defaecate in a private toilet, rather than at the bedside (or within the bed). Indeed, bedside commodes should only be used if the patient has mobility problems, and bed pans should only be used if the patient is on strict bed rest. Defaecation may be facilitated by adopting the "correct" toilet position (i.e. semi-squatting position, knees above hips, leaning slightly forward) [36], and this can be facilitated by the use of a foot stool [9]. It is essential that a foot stool is used whenever a raised toilet seat is employed.

Recommendation 4 - Lifestyle changes (e.g. dietary fibre, exercise) have a limited role in patients with advanced cancer [Level of evidence - V; category of guideline - suggestion]. Observational studies of patients with advanced cancer have also show an association between constipation and inadequate nutrition (low fibre diet), inadequate hydration, and decreased physical activity [35]. Moreover, there is evidence that increasing fibre intake, increasing fluid intake (in dehydrated patients), and increasing physical activity may improve functional constipation (but not opioid-induced constipation) [9]. However, these strategies are generally unsuitable for patients with advanced cancer [16], and indeed there is no evidence that these strategies are effective in this group of patients. 


\section{Recommendation 5 - Reversible causes of constipation should be treated, and potential aggravating factors should be minimised [Level of evidence - V; category of guideline - suggestion].}

In some cases of secondary constipation it will be possible to treat the underlying condition, or discontinue the constipating medication, and so ameliorate the constipation. It should be noted that reducing the dose of opioid invariably does not improve opioid-induced constipation, although "switching" the opioid sometimes improves opioid-induced constipation [37].

Recommendation 6 - Conventional laxatives should be considered as first-line treatment in patients with functional constipation [Level of evidence - I; category of guideline recommendation; data primarily from the general population].

Currently, there is relatively little data on the use of conventional laxatives in patients with advanced cancer. Thus, the Cochrane systematic review of laxatives for the management of constipation in people receiving palliative care (almost exclusively patients with advanced cancer) concluded that "there was no evidence on whether individual laxatives were more effective than others or caused fewer adverse effects" [38].

However, on the basis of data in the general population [39,40], expert opinion (gastroenterology) [6,41], expert opinion (palliative care) [42], and extensive clinical experience in patients with advanced cancer, the group recommend the use of polyethylene glycol formulations as the first-line treatment for constipation in patients with advanced cancer. [It should be noted, however, that none of the studies in the aforementioned Cochrane systematic review involved polyethylene glycol formulations [38]].

Nevertheless, as stated above, the management of constipation should be individualised, since certain practical issues can limit the use of polyethylene glycol formulations (e.g. volume of fluid, taste / consistency), as well as certain adverse effects (e.g. diarrhoea, abdominal distension) [2]. The same considerations apply to all other conventional laxatives (and indeed all interventions for constipation). Table 3 shows the British National Formulary categories of laxatives with examples for each category [43]. 
Recommendation 7 - Conventional laxatives should be considered as first-line treatment in patients with secondary constipation [Level of evidence - V; category of guideline suggestion].

Management of secondary constipation primarily involves treating the underlying condition. If this is not possible, or if the patient remains constipated, then management of secondary constipation should follow that of functional constipation (with the exception of opioidinduced constipation - see below).

Recommendation 8 - If patients with functional constipation / secondary constipation do not respond to first-line conventional laxatives, then re-assess the patient and consider adding or switching to another conventional laxative or specialist medication (e.g. linaclotide, lubiprostone, prucalopride) [Level of evidence - V; category of guideline suggestion].

If patients do not respond to optimal dosing of first-line conventional laxatives, then the options for ongoing management involve the use of conventional laxatives from a different class of drug (Table 3), or a more "specialist" medication (e.g. linaclotide, lubiprostone, prucalopride) [44]. The latter should generally be prescribed / monitored by clinicians with experience in utilising such specialist medication.

\section{Recommendation 9 - Peripherally-acting mu-opioid receptor antagonists (PAMORAs)} should always be considered in patients with opioid-induced constipation [Level of evidence - I; category of guideline - recommendation; data from patients with cancer, and patients with advanced disease].

The peripherally-acting mu-opioid receptor antagonists (PAMORAs) reverse the effects of opioids on the gastrointestinal tract, and so in theory should be the optimum treatment for opioid-induced constipation. A number of different PAMORAs have been developed to treat opioid-induced constipation, including subcutaneous methylnaltrexone [45], oral methylnaltrexone [46], oral naloxegol [47], and oral naldemedine [48]. Studies of PAMORAs have been undertaken in patients with advanced disease, and also in patients with cancer pain (as opposed to non-malignant pain). Of note, there is no data to suggest that the efficacy / tolerability of PAMORAs is population-dependent.

The Cochrane systematic review of mu-opioid antagonists for opioid-induced bowel dysfunction in people with cancer and people receiving palliative care concluded that "there 
is moderate-quality evidence that methylnaltrexone improves bowel function in people receiving palliative care in the short term and over two weeks, and low-quality evidence that it does not increase adverse events", and that "there is moderate-quality evidence to suggest that, taken orally, naldemedine improves bowel function over two weeks in people with cancer and OIBD (opioid-induced bowel dysfunction) but increases the risk of adverse events" [49].

Another systematic review of treatments for opioid-induced constipation concluded "muopioid receptor antagonists to be safe and effective for the treatment of OIC" [50]. This systematic review included a larger range of studies than the Cochrane systematic review (23 versus eight randomised controlled trials) [49], and calculated numbers needed to treat (NNT) of 3.4 (95\% CI: 3-6) for methylnaltrexone, 7 (95\% CI: 4-26) for naloxegol, and 5 (95\% CI: 4 8) for naldemedine, and the number needed to harm of 20 for all medications [50]. The response to PAMORAs was affected by the dose of opioid (increased efficacy in patients on higher doses), and the previous response to laxatives (increased efficacy in patients "refractory to laxatives") [50]. It should be noted that the aforementioned NNTs were calculated using different primary endpoints (and so are not directly comparable) [50].

In 2015, the National Institute for Health and Care Excellence (NICE) reviewed the clinical and health economic data on oral naloxegol, and concluded that "naloxegol is recommended, within its marketing authorisation, as an option for treating opioid induced constipation in adults whose constipation has not adequately responded to laxatives" [29]. The technology appraisal guidance states that "an inadequate response is defined as opioid-induced constipation symptoms of at least moderate severity in at least 1 of the 4 stool symptom domains (that is, incomplete bowel movement, hard stools, straining or false alarms) while taking at least 1 laxative class for at least 4 days during the previous 2 weeks".

Conventional opioid antagonists (e.g. naloxone) have been used to manage OIC [51], and have even been incorporated into analgesic formulations to prevent / manage OIC [52]. However, conventional opioid antagonists particularly in high doses may reverse analgesia, and precipitate withdrawal (and so their role is somewhat limited) [51].

\section{Recommendation 10 - If patients with opioid-induced constipation do not respond to} PAMORAs, then re-assess the patient and consider adding or switching to a conventional 
laxative or specialist medication (e.g. lubiprostone, prucalopride) [Level of evidence - V; category of guideline - suggestion].

Systematic review data suggests that many patients with opioid-induced constipation do not achieve an adequate response with PAMORAs [49,50], which may reflect the fact that the constipation is not opioid-induced, or more likely that the constipation is multi-factorial in aetiology [53]. Thus, some patients will benefit from the addition of a conventional laxative to the PAMORA, whilst others will require the substitution of a conventional laxative for the PAMORA. Of note, lubiprostone and prucalopride have efficacy in opioid-induced constipation (as well as functional constipation) [54,55].

Recommendation 11 - Patients prescribed opioid analgesics should be routinely coprescribed laxatives (or a PAMORA) [Level of evidence - IV; category of guideline suggestion].

As constipation is a common adverse effect of opioid analgesics, it is recommended that patients starting opioid analgesics should be co-prescribed conventional laxatives [56,57]. Surprisingly, there is only limited evidence to support this recommendation [58].

Currently, there is no data to support the co-prescribing of PAMORAs, although in theory this would be a more effective strategy to prevent opioid-induced constipation (than the coprescribing of conventional laxatives) [14].

Recommendation 12 - Suppositories / enemas should only be used in patients with evidence of stool in the rectum and / or descending colon that have not responded to other interventions [Level of evidence - V; category of guideline - suggestion].

The evidence base for rectal interventions (i.e. suppositories, enemas) is somewhat limited, and there are no randomised controlled trials in patients with advanced cancer [38]. Rectal interventions are generally reserved for patients that have not responded to other interventions $[6,42]$, with suppositories used in patients with stool in the rectum, and enemas used for patients with stool in the descending colon [4]. A variety of different formulations are available (Table 3) $[4,43]$, and there are a number of local and systemic contraindications (e.g. intestinal obstruction, thrombocytopenia) [4].

Trans-anal irrigation (TRI) may have a role in some patients, but the evidence to support its use in clinical practice is limited [59]. 


\section{Recommendation 13 - Other interventions should generally only be used in patients with}

“resistant” constipation [Level of evidence - V; category of guideline - suggestion].

A wide range of other interventions have been used to manage constipation in the general population, and in patients with advanced cancer, i.e. traditional remedies, complementary therapies, and other pharmacological interventions. Interventions that have been reported as being effective in patients with advanced cancer include acupuncture (and associated techniques) [60], aroma massage [61], petroleum jelly [62], amidotrizoate / diatrizoate [63], and neostigmine [64]. However, the evidence base (and indeed experience) with these interventions is more limited than with previously discussed interventions.

Recommendation 14 - All patients with constipation should be regularly re-assessed [Level of evidence - V; category of guideline - suggestion].

The objectives of re-assessment are to determine: a) changes in the clinical condition; $b$ ) the effectiveness of any intervention; and c) assess the tolerability of any intervention. Inadequate re-assessment may result in continuation of ineffective interventions (and persistence of constipation).

An expert consensus panel has recommended that the Bowel Function Index be used to assess the effectiveness of interventions for opioid-induced constipation, with a score of $>30$ triggering a change in intervention (as this represents an "inadequate response") $[65,66]$. However, other outcome measures may be more appropriate in some individuals [65].

\section{Recommendation 15 - Patients with ongoing "resistant" constipation should be referred to a specialist for further investigation / management [Level of evidence - V; category of guideline - suggestion].}

\section{CONCLUSION}

Constipation is a common problem in patients with advanced cancer, and is the cause of significant morbidity in this group of patients. The recommendations in this paper are wherever possible based on studies in patients with advanced cancer, and if such data was not available extrapolated from other groups of patients. However, patients with advanced cancer are different from other groups of patients, including patients with other life-limiting conditions. Thus, further research is required to validate these recommendations. 


\section{CONFLICT OF INTEREST}

ADavies has received personal fees and research funding from Kyowa Kirin; CL has received personal fees from Kyowa Kirin; ADickman has received personal fees from Kyowa Kirin; DF has received personal fees from Novartis, Pfizer and Roche.

\section{REFERENCES}

[1]. Laugsand EA, Jakobsen G, Kaasa S, Klepstad P (2011) Inadequate symptom control in advanced cancer patients across Europe. Support Care Cancer 19: 2005-2014.

[2]. Noguera A, Centeno C, Librada S, Nabal M (2010) Clinical use of oral laxatives in palliative care services in Spain. Support Care Cancer 18: 1491-1494.

[3]. Sera L, McPherson ML (2018) Management of opioid-induced constipation in hospice patients. Am J Hosp Palliat Med 35: 330-335.

[4]. Larkin PJ, Cherny NI, La Carpia D, Guglielmo M, Ostgathe C, Scotte F et al (2018)

Daignosis, assessment and management of constipation in advanced cancer: ESMO Clinical Practice Guidelines. Ann Oncol 29(Suppl 4): iv94-iv108.

[5]. Anonymous (2010) Oxford Concise Medical Dictionary, 8th edition. Oxford University Press, Oxford.

[6]. Lindberg G, Hamid SS, Malfertheiner P, Thomsen OO, Fernandez LB, Garisch J et al (2011) World Gastroenterology Organisation global guideline: Constipation: a global perspective. J Clin Gastroenterol 45: 483-487.

[7]. Walter S, Hallbook O, Gotthard R, Bergmark M, Sjodahl R (2002) A population-based study on bowel habits in a Swedish community: prevalence of faecal incontinence and constipation. Scand J Gastroenterol 37: 911-916.

[8]. Lee TH, Choi SC, Park MI, Park KS, Shin JE, Kim SE et al (2014) Constipation misperception is associated with gender, marital status, treatment utilization and constipation symptoms experienced. J Neurogastroenterol Motil 20: 379-387.

[9]. Lacy BE, Mearin F, Chang L, Chey WD, Lembo AJ, Simren M et al (2016) Bowel Disorders. Gastroenterology 150: 1393-1407.

[10]. Farmer AD, Drewes AM, Chiarioni G, De Giorgio R, O’Brien T, Morlion B et al (2018) Pathophysiology and management of opioid-induced constipation: European expert consensus statement. United European Gastroenterol J [Epub ahead of print]. [11]. Laugsand EA, Skorpen F, Kaasa S, Sabatowski R, Strasser F, Fayers P et al (2015) Genetic and non-genetic factors associated with constipation in cancer patients receiving opioids. Clin Transl Gastroenterol 6: e90. 
[12]. Hadley G, Derry S, Moore RA, Wiffen PJ (2013) Transdermal fentnayl for cancer pain. Cochrane Database of Systematic Reviews Issue 10. Art. No.: CD010270.

[13]. Fallon MT, Hanks GW (1999) Morphine, constipation and performance status in advanced cancer patients. Palliat Med 13: 159-160.

[14] Camilleri M, Drossman DA, Becker G, Webster LR, Davies AN, Mawe GM (2014)

Emerging treatments in neurogastroenterology: a multidisciplinary working group consensus statement on opioid-induced constipation. Neurogastroenterol Motil 26: 1386-1395. [15]. Suares NC, Ford AC (2011) Prevalence of, and risk factors for, chronic idiopathic constipation in the community: systematic review and meta-analysis. Am J Gastroenterol 106: 1582-1591.

[16]. Larkin PJ, Sykes NP, Centeno C, Ellershaw JE, Elsner F, Eugene B et al (2008) The management of constipation in palliative care: clinical practice recommendations. Palliat Med 22: 796-807.

[17]. Oosten AW, Oldenmenger WH, Mathijssen RH, van der Rijt CC (2015) A systematic review of prospective studies reporting adverse events of commonly used opioids for cancerrelated pain: a call for the use of standardized outcome measures. J Pain 16: 935-946. [18] Johanson JF, Kralstein J (2007) Chronic constipation: a survey of the patient perspective. Aliment Pharmacol Ther 25: 599-608.

[19]. Davies A, Webber K (2015) Stercoral perforation of the colon: a potentially fatal complication of opioid-induced constipation. J Pain Symptom Manage 50: 260-262. [20]. Yamada N, Nakamura M, Ishikura K, Ota M, Yazu T, Ota S et al (2005) Triggers of acute pulmonary thromboembolism devleoped in hospital, with focusing on toliet activities as triggering acts. Int J Cardiol 98: 409-411.

[21]. Dhingra L, Shuk E, Grossman B, Strada A, Wald E, Portenoy A et al (2013) A qualitative study to explore psychological distress and illness burden associated with opioidinduced constipation in cancer patients with advanced disease. Palliat Med 27: 447-456. [22]. Friedrichsen M, Erichsen E (2004) The lived experience of constipation in cancer patients in palliative hospital-based home care. Int J Palliat Nurs 10: 321-325. [23]. Hjalte F, Berggren A-C, Bergendahl H, Hjortsberg C (2010) The direct and indirect costs of opioid-induced constipation. J Pain Symptom Manage 40: 696-703.

[24]. Hess B, Bernardi M, Klotz H-P (2011) Attitude of Swiss physicians towards opioidinduced constipation: a national survey. Eur J Intern Med 22: 527-531.

[25]. Multinational Association for Supportive Care in Cancer Guidelines Policy: https://www.mascc.org/assets/Toolbox/PoliciesForms/mascc_guideline_policy_2018.pdf 
Accessed $4^{\text {th }}$ November 2018.

[26]. National Cancer Institute Dictionary of Cancer

https://www.cancer.gov/publications/dictionaries/cancer-terms

Accessed $4^{\text {th }}$ November 2018.

[27]. Cochrane Database of Systematic Reviews:

https://www.cochranelibrary.com/cdsr/about-cdsr

Accessed $4^{\text {th }}$ November 2018.

[28]. Cochrane Central Register of Controlled Trials (CENTRAL):

https://www.cochranelibrary.com/central/about-central

Accessed $4^{\text {th }}$ November 2018.

[29]. National Institute for Health and Care Excellence (2015) Naloxegol for treating opioidinduced constipation. Technology Appraisal Guidance [TA345]. NICE, London.

[30]. Lewis SJ, Heaton KW (1997) Stool form scale as a useful guide to intestinal transit time. Scand J Gastroenterol 32: 920-924.

[31]. Clark K, Currow DC, Talley NJ (2010) The use of digital rectal examinations in palliative care patients. J Palliat Med 13: 797.

[32]. Palsson OS, Whitehead WE, van Tilburg MA, Chang L, Chey W, Crowell MD et al (2016) Development and validation of the Rome IV Diagnostic Questionnaire for adults. Gastroenterology 150: 1481-1491.

[33]. Starreveld JS, Pols MA, Van Wijk HJ, Bogaard JW, Poen H, Smout AJ (1990) The plain abdominal radiograph in the assessment of constipation. Z Gastroenterol 28:335-338. [34]. Nagaviroj K, Yong WC, Fassbender K, Zhu G, Oneschuk D (2011) Comparison of the Constipation Assessment Scale and plain abdominal radiography in the assessment of constipation in advanced cancer patients. J Pain Symptom Manage 42: 222-228.

[35]. Dzierzanowski T, Cialkowska-Rysz A (2015) Behavioral risk factors of constipation in palliative care patients. Support Care Cancer 23: 1787-1793.

[36]. Emmanuel A (2011) Current management strategies and therapeutic targets in chronic constipation. Therap Adv Gastroenterol 4: 37-48.

[37]. Cherny N, Ripamonti C, Pereira J, Davis C, Fallon M, McQuay H et al (2001)

Strategies to manage the adverse effects of oral morphine: an evidence-based report. J Clin Oncol 19: 2542-2554.

[38]. Candy B, Jones L, Larkin PJ, Vickerstaff V, Tookman A, Stone P (2015) Laxatives for the management of constipation in people receiving palliative care. Cochrane Database of Systematic Reviews Issue 5. Art. No.: CD003448 
[39]. Brandt LJ, Prather CM, Quigley EM, Schiller LR, Shoenfeld P, Talley NJ (2005)

Systematic review on the management of chronic constipation in North America. Am J Gastroenterol 100: S5-S22.

[40]. Lee-Robichaud H, Thomas K, Morgan J, Nelson RL (2010) Lactulose vesrus polyethylene glycol for chronic constipation. Cochrane Database of Systematic Reviews Issue 7. Art. No.: CD007570.

[41]. American Gastroenterological Association (2013) American Gastroenterological Association medical position statement on constipation. Gastroenerology 144: 211-217. [42]. Librach SL, Bouvette M, De Angelis C, Farley J, Oneschuk D, Pereira JL et al (2010) Consensus recommendations for the management of constipation in patients with advanced, progressive illness. J Pain Symptom Manage 40: 761-773.

[43]. British Medical Association and the Royal Pharmaceutical Society (2017) British National Formulary 74. Pharmaceutical Press, Basingstoke.

[44]. Ford AC, Suares NC (2011) Effect of laxatives and pharmacological therpaies in chronic idiopathic constipation: systematic review and meta-analysis. Gut 60: 209-218. [45]. Thomas J, Karyer S, Cooney GA, Chamberlain BH, Watt CK, Slatkin NE et al (2008) Methylnaltrexone for opioid-induced constipation in advanced illness. N Engl J Med 358: 2332-2343.

\section{Send to}

[46]. Rauck R, Slatkin NE, Stambler N, Harper JR, Israel RJ (2017) Randomized, doubleblind trial of oral methylnaltrexone for the treatment of opioid-induced constipation in patients with chronic noncancer pain. Pain Pract 17: 820-828.

[47]. Chey WD, Webster L, Sostek M, Lappalainen J, Barker PN, Tack J (2014) Naloxegol for opioid-induced constipation in patients with noncancer pain. N Engl J Med 370: $2387-$ 2396.

[48]. Katakami N, Harada T, Murata T, Shinozaki K, Tsutsumi M, Yokota T et al (2017) Randomized phase III and extension studies of naldemedine in patients with opioid-induced constipation and cancer. J Clin Oncol 35: 3859-3866

[49]. Candy B, Jones L, Vickerstaff V, Larkin PJ, Stone P (2018) Mu-opioid anatagonists for opioid-induced bowel dysfunction in people with cancer and people receiving palliative care. Cochrane Database of Systematic Reviews Issue 6. Art. No.: CD006332.

[50]. Nee J, Zakari M, Sugarman MA, Whelan J, Hirsch W, Sultan S et al (2018) Efficacy of treatments for opioid-induced constipation: systematic review and meta-anlysis. Clin Gastroenterol Hepatol 16: 1569-1584. 
[51]. Sykes NP (1996) An investigation of the ability of oral naloxone to correct opioidrelated constipation in patients with advanced cancer. Palliat Med 10: 135-144.

[52]. Dupoiron D, Stachowiak A, Loewenstein O, Ellery A, Kremers W, Bosse B et al (2017) A phase III randomized controlled study on the efficacy and improved bowel function of prolonged-release (PR) oxycodone-naloxone (up to 160/80 mg daily) vs oxycodone PR. Eur J Pain 21: 1528-1537.

[53]. Clark K, Byfieldt N, Dawe M, Currow DC (2012) Treating constipation in palliative care: the impact of other factors aside from opioids. Am J Hosp Palliat Care 29: 122-125. [54]. Cryer B, Katz S, Vallejo R, Popescu A, Ueno R (2014) A randomized study of lubiprostone for opioid-induced constipation in patients with chronic noncancer pain. Pain Med; 15: 1825-1834.

[55]. Sloots CE, Rykx A, Cools M, Kerstens R, De Pauw M (2010) Efficacy and safety of prucalopride in patients with chronic noncancer pain suffering from opioid-induced costipation. Dig Dis Sci; 55: 2912-2921

[56]. Caraceni A, Hanks G, Kaasa S, Bennett MI, Brunelli C, Cherny N et al (2012) Use of opioid analgesics in the treatment of cancer pain: evidence-based recommendations from the EAPC. Lancet Oncol 13: e58-e68.

[57]. National Comprehensive Cancer Network (2018) Adult Cancer Pain Version 1.2018. National Comprehensive Cancer Network, Plymouth Meeting.

[58]. Ishihara M, Ikesue H, Matsunaga H, Suemaru K, Kitaichi K, Suetsugu K et al (2012) A multi-institutional study analyzing effect of prophylactic medication for prevention of opioidinduced gastrointestinal dysfunction. Clin J Pain 28: 373-381.

[59]. Wilkinson-Smith V, Bharucha AE, Emmanuel A, Knowles C, Yiannakou Y, Corsetti M (2018) When all else seems lost: management of refractory constipation - surgery, rectal irrigation, percutaneous endoscopic colostomy, and more. Neurogastroenterol Motil 30: e13352.

[60]. Lau CH, Wu X, Chung VC, Liu X, Hui EP, Cramer H et al (2016) Acupuncture and related therapies for symptom management in palliative cancer care: systematic review and meta-analysis. Medicine (Baltimore) 95: e2901.

[61]. Lai TK, Cheung MC, Lo CK, Ng KL, Fung YH, Tong M et al (2011) Effectiveness of aroma massage on advanced cancer patients with constipation: a pilot study. Complement Ther Clin Pract 17: 37-43. 
[62]. Tavares CN, Kimbrel JM, Protus BM, Grauer PA (2014) Petroleum jelly (vaseline balls) for the treatment of constipation: a survey of hospice and palliative care practitioners. Am J Hosp Palliat Care 31: 797-803.

[63]. Mercadante S, Ferrera P, Casuccio A (2011) Effectiveness and tolerability of amidotrizoate for the treatment of constipation resistant to laxatives in advanced cancer patients. J Pain Symptom Manage 41: 421-425.

[64]. Rubiales AS, Hernansanz S, Gutierrez C, Del Valle ML, Flores LA (2006) Neostigmine for refractory constipation in advanced cancer patients. J Pain Symptom Manage 32: 204205.

[65]. Argoff CE, Brennan MJ, Camilleri M, Davies A, Fudin J, Galluzzi KE et al (2015) Consensus recommendations on initiating prescription therapies for opioid-induced constipation. Pain Med 16: 2324-2337.

[66]. Rentz AM, Yu R, Muller-Lissner S, Leyendecker P (2009) Validation of the Bowel Function Index to detect clinically meaningful changes in opioid-induced constipation. J Med Econ 12: 371-383. 
1. Constipation - mesh

OR (search terms 2-50)

2. Defecation - mesh

3. Laxatives - mesh

4. Cathartics - mesh

5. Aperients - key word

6. Bulk forming laxatives - keyword

7. Ispaghula husk - keyword

8. Methylcellulose - mesh

9. Sterculia - mesh

10. Frangula - mesh

11. Chloride channel agonists - mesh

12. Lubiprostone - mesh

13. Osmotic laxatives - keyword

14. Lactulose - mesh

15. Macrogol-keyword

16. Polyethylene glycols - mesh

17. Magnesium hydroxide - mesh

18. Sodium acid phosphate - keyword

19. Serotonin 5-HT4 receptor agonists - mesh

20. Prucalopride - key word

21. Stimulant laxatives - keyword

22. Bisacodyl - mesh

23. Co-danthramer-keyword

24. Dantron - keyword

25. Poloxamer - mesh

26. Co-danthrusate - keyword

27. Glycerol - mesh

28. Senna-keyword

29. Senna extract - mesh

30. Senna plant - mesh

31. Anthraquinones - mesh 
32. Sodium picosulfate - keyword

33. Opioid receptor antagonists - keyword

34. Narcotic antagonists - mesh

35. Peripherally acting mu opioid receptor antagonist - keyword

36. Methylnaltrexone-keyword

37. Naloxegol-keyword

38. Softening drugs - keyword

39. Arachis oil - keyword

40. Docusate sodium - keyword

41. Dioctyl sulfosuccinic acid - mesh

42. Liquid paraffin - keyword

43. Mineral oil - mesh

44. Bowel cleansing - keyword

45. Enema-mesh

46. Suppositories - mesh

47. Dietary fiber - mesh

48. Psyllium - keyword

49. Fecal impaction - mesh

50. Disimpaction - key word

AND (search terms 51-52)

51. Neoplasms - mesh

OR

52. Cancer - key word 
Levels of evidence

\begin{tabular}{|c|l|}
\hline I & $\begin{array}{l}\text { Evidence obtained from meta-analysis of multiple, well-designed, } \\
\text { controlled studies; randomized trials with low false-positive and } \\
\text { false-negative errors (high power) }\end{array}$ \\
\hline II & $\begin{array}{l}\text { Evidence obtained from at least one-well designed experimental } \\
\text { study; randomized trials with high false-positive and/or false- } \\
\text { negative errors (low power) }\end{array}$ \\
\hline III & $\begin{array}{l}\text { Evidence obtained from well-designed, quasi-experimental studies, } \\
\text { such as nonrandomized, controlled single-group, pretest-posttest } \\
\text { comparison, cohort, time, or matched case-control series }\end{array}$ \\
\hline IV & $\begin{array}{l}\text { Evidence obtained from well-designed, non-experimental studies, } \\
\text { such as comparative and correlational descriptive and case studies }\end{array}$ \\
\hline V & \begin{tabular}{l} 
Evidence obtained from case reports and clinical examples \\
\hline
\end{tabular} \\
\hline
\end{tabular}

Categories of guidelines

\begin{tabular}{|l|l|}
\hline Recommendation & $\begin{array}{l}\text { Reserved for guidelines that are based on } \\
\text { Level I or Level II evidence }\end{array}$ \\
\hline Suggestion & $\begin{array}{l}\text { Used for guidelines that are based on Level } \\
\text { III, Level IV, and Level V evidence; this } \\
\text { implies panel consensus on the } \\
\text { interpretation of this evidence }\end{array}$ \\
\hline No guideline possible & $\begin{array}{l}\text { Used when there is insufficient evidence on } \\
\text { which to base a guideline; this implies (1) } \\
\text { that there is little or no evidence regarding } \\
\text { the practice in question, or (2) that the panel } \\
\text { lacks consensus on the interpretation of } \\
\text { existing evidence }\end{array}$ \\
\hline
\end{tabular}


Decreased small bowel motility

Decreased electrolyte \& water secretion small bowel

Increased tone ileocaecal valve

Decreased large bowel motility

Increased electrolyte \& water absorption large bowel

Increased tone anal sphincter

Reduced anorectal sensitivity (to distension)

Box 1 - Pathophysiology opioid-induced constipation.

Frequency of bowel movements?

Straining with bowel moments?

Consistency of stool*?

Sensation of incomplete evacuation?

Sensation of blockage in rectum / anus?

Current / previous use of laxatives?

Current / previous use of other measures (e.g. traditional remedies, complementary remedies)?

[Change in bowel function since starting opioid analgesia?]

* Utilise Bristol Stool Chart

Box 2 - Questions for assessing constipation. 
- All patients with advanced cancer should be regularly assessed for constipation [Level of evidence - V; category of guideline - suggestion].

- The management of constipation should be individualised [Level of evidence - V; category of guideline - suggestion].

- Patients should be offered adequate privacy, and appropriate equipment (e.g. commode, foot stool), to promote defaecation [Level of evidence - V; category of guideline - suggestion].

- Lifestyle changes (e.g. dietary fibre, exercise) have a limited role in patients with advanced cancer [Level of evidence - V; category of guideline - suggestion].

- Reversible causes of constipation should be treated, and potential aggravating factors should be minimised [Level of evidence - V; category of guideline suggestion].

- Conventional laxatives should be considered as first-line treatment in patients with functional constipation [Level of evidence - I; category of guideline recommendation].

- Conventional laxatives should be considered as first-line treatment in patients with secondary constipation [Level of evidence - V; category of guideline - suggestion].

- If patients with functional constipation / secondary constipation do not respond to first-line conventional laxatives, then re-assess the patient and consider adding or switching to another conventional laxative or specialist medication (e.g. linaclotide, lubiprostone, prucalopride) [Level of evidence - V; category of guideline suggestion].

- Peripherally-acting mu-opioid receptor antagonists (PAMORAs) should always be considered in patients with opioid-induced constipation [Level of evidence - I; category of guideline - recommendation].

- If patients with opioid-induced constipation do not respond to PAMORAs, then reassess the patient and consider adding or switching to a conventional laxative or specialist medication (e.g. lubiprostone, prucalopride) [Level of evidence - V; category of guideline - suggestion].

- Patients prescribed opioid analgesics should be routinely co-prescribed laxatives (or a PAMORA) [Level of evidence - IV; category of guideline - suggestion]. 
- Suppositories / enemas should only be used in patients with evidence of stool in the rectum and / or descending colon that have not responded to other interventions [Level of evidence - V; category of guideline - suggestion].

- Other interventions should generally only be used in patients with "resistant" constipation [Level of evidence - V; category of guideline - suggestion].

- All patients with constipation should be regularly re-assessed [Level of evidence $\mathrm{V}$; category of guideline - suggestion].

- Patients with ongoing "resistant" constipation should be referred to a specialist for further investigation / management [Level of evidence - V; category of guideline suggestion].

Table 1 - Recommendations for management of constipation in patients with advanced cancer. 


\begin{tabular}{|c|c|}
\hline $\begin{array}{l}\text { Rome IV criteria for functional } \\
\text { constipation }\end{array}$ & $\begin{array}{c}\text { Rome IV criteria for opioid-induced } \\
\text { constipation }\end{array}$ \\
\hline $\begin{array}{l}\text { 1. Must include } 2 \text { or more of the following: } \\
\text { a) Straining during more than one-fourth } \\
\text { ( } 25 \%) \text { of defecations } \\
\text { b) Lumpy or hard stools (BSFS } 1-2) \text { more } \\
\text { than one-fourth ( } 25 \%) \text { of defecations } \\
\text { c) Sensation of incomplete evacuation more } \\
\text { than one-fourth ( } 25 \%) \text { of defecations } \\
\text { d) Sensation of anorectal obstruction / } \\
\text { blockage more than one-fourth ( } 25 \%) \text { of } \\
\text { defecations } \\
\text { e) Manual maneuvers to facilitate more than } \\
\text { one-fourth ( } 25 \%) \text { of defecations (e.g. digital } \\
\text { evacuation, support of pelvic floor) } \\
\text { f) Fewer than } 3 \text { spontaneous bowel } \\
\text { movements per week } \\
\text { 2. Loose stools are rarely present without the } \\
\text { use of laxatives } \\
\text { 3. Insufficient criteria for irritable bowel } \\
\text { syndrome } \\
\text { Criteria fulfilled for the last } 3 \text { months with } \\
\text { symptom onset at least } 6 \text { months prior to } \\
\text { diagnosis. }\end{array}$ & $\begin{array}{l}\text { 1. New or worsening symptoms of } \\
\text { constipation when initiating, changing, or } \\
\text { increasing opioid therapy that must include } \\
2 \text { or more of the following: } \\
\text { a) Straining during more than one-fourth } \\
\text { ( } 25 \% \text { ) of defecations } \\
\text { b) Lumpy or hard stools (BSFS 1-2) more } \\
\text { than one-fourth ( } 25 \% \text { ) of defecations } \\
\text { c) Sensation of incomplete evacuation more } \\
\text { than one-fourth ( } 25 \% \text { ) of defecations } \\
\text { d) Sensation of anorectal obstruction / } \\
\text { blockage more than one-fourth ( } 25 \%) \text { of } \\
\text { defecations } \\
\text { e) Manual maneuvers to facilitate more than } \\
\text { one-fourth ( } 25 \%) \text { of defecations (e.g. digital } \\
\text { evacuation, support of pelvic floor) } \\
\text { f) Fewer than } 3 \text { spontaneous bowel } \\
\text { movements per week } \\
\text { 2. Loose stools are rarely present without } \\
\text { the use of laxatives }\end{array}$ \\
\hline
\end{tabular}

Table 2 - Rome IV diagnostic criteria for functional constipation and opioid-induced constipation [9]. 


\begin{tabular}{|c|c|}
\hline CATEGORY & EXAMPLES \\
\hline $\begin{array}{l}\text { Laxatives } \\
\text { Bulk-forming laxatives }\end{array}$ & $\begin{array}{l}\text { - } \text { Ispaghula husk (oral) } \\
\text { - } \text { Methylcellulose (oral) } \\
\text { - } \text { Sterculia (oral) } \\
\text { - } \text { Sterculia with frangula (oral) }\end{array}$ \\
\hline Osmotic laxatives & $\begin{array}{l}\text { - Lactulose (oral) } \\
\text { - Macrogol } 3350 \text { with potassium chloride, sodium bicarbonate } \\
\text { and sodium chloride (oral) } \\
\text { - Magnesium hydroxide (oral) } \\
\text { - Sodium acid phosphate with sodium phosphate (oral, enema) }\end{array}$ \\
\hline Softening laxatives & $\begin{array}{l}\text { - Aracus oil (enema) } \\
\text { - Docusate sodium (oral, enema) } \\
\text { - Liquid paraffin (oral) } \\
\text { - Liquid paraffin with magnesium hydroxide (oral) }\end{array}$ \\
\hline Stimulant laxatives & $\begin{array}{l}\text { - Bisacodyl (oral, enema, suppository) } \\
\text { - Co-danthramer (oral) } \\
\text { - Co-danthrusate (oral) } \\
\text { - Glycerol (suppository) } \\
\text { - Senna (oral) } \\
\text { - Senna with ispaghula husk (oral) } \\
\text { - Sodium picosulfate (oral) }\end{array}$ \\
\hline $\begin{array}{l}\text { Other drugs } \\
\text { Chloride-channel agonists }\end{array}$ & - Lubiprostone (oral) \\
\hline $\begin{array}{l}\text { Selective } 5-\mathrm{HT}_{4} \text { receptor } \\
\text { agonists }\end{array}$ & - Prucalopride (oral) \\
\hline Opioid receptor antagonists & $\begin{array}{l}\text { - Methylnaltrexone (subcutaneous) } \\
\text { - Naloxegol (oral) }\end{array}$ \\
\hline Bowel cleansing preparations & $\begin{array}{l}\text { - } \text { Citric acid with magnesium carbonate (oral) } \\
\text { - Macrogol } 3350 \text { with anhydrous sodium sulfate, ascorbic acid, } \\
\text { potassium chloride, sodium ascorbate and sodium chloride (oral) } \\
\text { - Macrogol } 3350 \text { with anhydrous sodium sulfate, potassium } \\
\text { chloride, sodium bicarbonate and sodium chloride (oral) } \\
\text { - Magnesium citrate with sodium picosulfate (oral) } \\
\text { - Bisacodyl (oral and suppository) } \\
\text { - Docusate sodium (oral, enema) } \\
\text { - Magnesium sulfate (oral) }\end{array}$ \\
\hline
\end{tabular}

Table 3 - Drugs used to treat constipation [adapted from reference 43]. 